status through divine right, but through blood, and they more than anyone fear the same fate.

No distinction is drawn between the Witches, the ordinary people or the refugees, they are part of the same continuum. The supernatural is simply the natural order of things; it is present in 1940 s suburban England as it is in Birnam Wood, the Witches are no more than housewives. The naked bodies that sit among the trees on the hill at the back of the stage still perplex me, but perhaps represent the closeness of man to the rest of the ecosystem. It is the branches from these trees which ultimately overcome Macbeth and he is destroyed only after a child has taken the sword from his hand and replaced it with a branch.

In the final act Macbeth asserts that life is empty and meaningless. Such a revelation only occurs after his violent struggle to make sense of his life through environmental gain and he now seems near to defeat. He accepts that he must now fight again for his own life, as he must once have done as a General. Macbeth is again restored in his role of soldier and is seen to be resolute. he must fight or die, which is something Lady Macbeth never came to terms with. She has opted out, preferring insanity to fear and guilt playing on a rational mind, with all the responsibility that entails. The sleep-walking scene shows her ritually expunging her guilt by scrubbing her hands, and her unbalanced mind is illustrated further by the way she continuously rights a chair which she sits on and falls to one side. Her pitiful state is now in marked contrast to the accepting Macbeth who again takes up the challenge with the natural order and this time loses.

\title{
Current Opinion in Psychiatry
}

\section{Database}

This computerised database is now available in the College Library where the staff will carry out literature searches on behalf of members. The database provides information on current psychiatric literature as assessed by experts throughout the world. Printouts of references can be provided.

\section{Care of the elderly}

The Institute of Human Ageing will be holding a conference entitled 'The Untouchables: Taboo Topics in Care of the Elderly' at Kensington and Chelsea Town Hall, London on 10 and 11 January 1991. A series of practice-based seminars on this subject will be held throughout the UK commencing
January 1991. Further information: Valerie S. Goldberg, Conference Organiser, The Institute of Human Ageing, University of Liverpool, PO Box 147, Liverpool L69 3BX (telephone 051794 5074; fax 051794 5077).

\section{Courses}

An intensive five day advanced course entitled 'Molecular and Cellular Pathology of Neurodegenerative and Neuropsychiatric Disease' will be held at the Institute of Psychiatry from 14-18 January 1991. Course fee: $£ 400$ (including lunch and refreshments).

A short course in neuroscience entitled 'Molecular
Neurobiology' will be held at the Institute of Psychiatry from 7-11 January 1991. Course fee: $£ 150$. Further information and registration forms for both courses: Mrs Lee Wilding, Conference Office, Institute of Psychiatry, De Crespigny Park, London SE5 8AF (telephone 071703 5411, extension 3170). 